Tersedia Secara Online di

http://ojs.unik-kediri.ac.id/index.php/jurmateks/index

JURMATEKS

http://dx.doi.org/10.30737/jurmateks

\title{
Pengujian Kuat Tekan Pada Beton Dengan Penambahan Limbah Marmer Dan Serat Batang Pisang
}

\author{
L. A. Utama ${ }^{1 *}$, A. I. Candra ${ }^{2}$, A. Ridwan ${ }^{3}$ \\ ${ }^{1,2,3}$ Fakultas Teknik, Universitas Kadiri. \\ Email:1*leogusta43@gmail.com
}

\section{A R T I C L E IN F O \\ Article history: \\ Artikel masuk \\ Artikel revisi \\ : $15-10-2020$ \\ : $19-10-2020$ \\ Artikel diterima : $20-10-2020$}

Keywords:

Marble Waste, Banana Rod

Fiber, Strong Press.

Style IEEE dalam mensitasi artikel ini: [13] A. I. Candra, A. Ridwan, S. Winarto, and Romadhon, "Correlation of Concrete Strength and Concrete Age K-300 Using Sikacim ${ }^{\circledR}$ Concrete Additive and Master Ease 5010," J. Phys. Conf. Ser., vol. 1569, no. 4, 2020, doi: $10.1088 / 1742-$

6596/1569/4/042032.

\begin{abstract}
A B S TRACT
In the era of technological developments, concrete is one of the primary components of a construction that takes year to unfold. Thus needs to be innovation of concrete making materials. These additional material are marble waste and banana rod fibers. Marble waste is a waste from the manufacture of ornamental stone whose waste can utilized for concrete making mixture materials. While banana rod are environmental waste that is not utilized properly. The aim of this study is to find out the effect of adding marble waste and banana stem fibers to the strong value of concrete press and slump, with a percentage of 10\%, 20\%, 30\% of the rough aggregate weight. Strong press testing was carried out at 28 days concrete life with an initial quality of $F C^{\prime} 18.68$ Mpa. The results showed that the highest press strength was obtained from the addition of marble waste and banana stem fiber at a percentage of $10 \%$ which is $17.94 \mathrm{Mpa}$. The conclusion of this study strongly press experienced a decrease from percentage $10 \%, 20 \%, 30 \%$ sequentially.
\end{abstract}

\section{A B S T R A K}

Di era perkembangan teknologi, beton merupakan salah satu komponen utama dalam sebuah konstruksi yang dimana disetiap tahunnya mengalami perkembangan pesat. Dengan begitu perlu adanya inovasi dari bahan pembuatan beton. Bahan tambahan tersebut merupakan limbah marmer dan serat batang pisang. Limbah marmer merupakan limbah dari pembuatan batu hias yang limbahnya mampu dimanfaatkan untuk bahan campuran pembuatan beton sedangkan serta batang pisang merupakan limbah lingkungan yang tidak dimanfaatkan dengan baik. Tujuan dari penelitian ini adalah untuk mengetahui pengaruh penambahan limbah marmer dan serat batang pisang terhadap nilai kuat tekan dan slump beton, dengan prosentase $10 \%, 20 \%$, $30 \%$ dari berat agregat kasar. Pengujian kuat tekan dilakukan pada umur beton 28 hari dengan mutu awal fc' 18,68 Mpa. Hasil 
penelitian menunjukkan bahwa kuat tekan tekan tertinggi diperoleh dari penambahan limbah marmer dan serat batang pisang pada prosentase $10 \%$ yaitu $17,94 \mathrm{Mpa}$. Kesimpulan dari penelitian ini kuat tekan mengalami penurunan dari prosentase $10 \%, 20 \%, 30 \%$ secara berurutan.

\section{Pendahuluan}

Di era perkembangan teknologi sekarang ini, kebutuhan beton mengalami peningkatan yang cukup signifikan dalam pembangunan infrastruktur, karena beton sendiri merupakan komponen utama sebuah struktur. Hal tersebut mendorong penulis untuk menghadirkan sebuah inovasi baru. Penelitian ini diharapkan dapat menjadi sebuah ide baru yang dapat menunjang perkembangan konstruksi. Bila pembangunan infrastruktur terus berkembang maka dikhawatirkan akan terjadi kekurangan pasokan bahan agregat. Penggunaan agregat alternatif dapat mengurangi kerusakan alam yang disebabkan dari pengambilan dan pengerukan batu alam. Selain itu penggunaan agregat alternatif dapat mengurangi biaya konstruksi [1]. Maka dari itu diperlukan inovasi baru dari beton dengan adanya penambahan bahan dasar pembuatan beton limbah marmer dan serta batang pisang.

Dalam perkembangan untuk mendapatkan material yang dipilih sebagai bahan bangunan yang dapat diandalkan dan memenuhi tuntutan jaman ,maka beton merupakan batu buatan yang masih dipilih sebagai bahan /material bangaunan [2]. Tujuan dari penelitian eksploratif ini adalah untuk menyelidiki dan menilai kinerja relatif dari berbagai DSA dalam beton bertulang baja di bawah dua tingkat khas yang terkontaminasi garam [3]. Dalam pembuatan campuran beton sebelumnya harus dilakukan pengujian terhadap material penyusun yang digunakan, untuk memperoleh data-data agregat yang memungkinkan agregat dapat digunakan atau tidak dan dari data-data material tersebut dilakukan perhitungan desain campuran (mix design), yang pada akhirnya akan diperoleh kebutuhan agregat berupa perbandingan berat maupun perbandingan volume yang dapat digunakan pada proses pencampuran beton [4]. Bahan beton yang lebih berkesinambungan dan ramah lingkungan dapat dibuat dengan mengurangi pemakaian agregat kasar alami (NCA). Reduc-tion ini dapat diganti dengan pemakaian rial pasangan daur ulang dan bahan konstruksi "hijau" seperti serat alami [5]. Dengan penambahan mineral additive ke dalam adukan beton merupakan salah satu jalan untuk menambah mutu dan kekuatan beton [6].

Kemajuan teknologi dan bahan baru telah menyebabkan banyak kemajuan di bidang kekuatan, daya tahan, dan konsistensi produksi. Saat ini, beton seluler ringan (LCC) mendapatkan popularitas dalam banyak aplikasi konstruksi seperti untuk mengurangi tekanan 
bumi, meminimalkan kekuatan dinamis, meminimalisir keruntuhan, dan menyerap kekuatan gempa dalam struktur bawah permukaan. Sebagai hasil dari aplikasi baru ini, pemahaman yang lebih baik diperlukan mengenai sifat rekayasa dari bahan-bahan ini [7]. Karena beton merupakan komposit, maka kualitas beton sangat tergantung dari kualitas masing-masing material pembentuk [8]. Bahan konstitu-ent utama yang secara signifikan mempengaruhi kepadatan beton adalah jenis agregat dalam campuran [9]. Berdasarkan hasil analisa pengaruh bahan tambahan dalam campuran beton didapatkan bahwa beton yang ditambahkan limbah marmer dan serat batang pisang mempunyai kuat tekan yang bervariasi.

Dalam penelitian ini digunakan limbah marmer dan serat batang pisang sebagai bahan tambahan dalam campuran beton. Upaya pemanfaatan kembali karena adanya observasi terkait penanganan masalah lingkungan yang bilamana dapat berdampak di kemudian hari.

Limbah marmer merupakan jenis batuan alam yang tebentuk akibat pengkristalan dari batu kapur yang mengalami pemanasan dan tekanan yang menyebabkan perubahan pada batu tersebut, sehingga menyebabkan perubahan tekstur dan variasi warnanya. Dimana batu marmer mampu dimanfaatkan menjadi bahan kerajinan pabrik industry namun, limbah dari hasil bekas kerajinan pabrik industry ini tidak dimanfaatkan dengan baik karena sudah tidak terpakai lagi. Marmer diperoleh dari alam melalui kegiatan penambangan. Hasil penambangan berupa bongkahan-bongkahan batu [10].

Meningkatnya penggunaan komposit fiber reinforced polymer (FRP) untuk memperkuat dan memperbaiki struktur rein-forced concrete (RC) yang ada telah mendorong upaya penelitian exten-sive dalam tiga dekade terakhir [11]. Bahan-bahan yang dicampurkan kedalam campuran beton yang berfungsi untuk mengubah ataupun memperbaiki sifat beton agar lebih cocok dengan kebutuhan atau pekerjaan tertentu disebut dengan bahan tambah beton (admixture) [12]. sehingga ketika tidak mencapai waktu maksimum tetapi beton diberikan beban yang berlebihan ada kemungkinan bahwa beton akan runtuh dan runtuh [13].

Serat Batang Pisang merupakan hasil alam / panen dari warga yang seringkai hanya hanya diambil buahnya. Serat batang pisang merupakan jenis serat yang berkualitas baik, dan merupakan salah satu bahan potensial alternatif yang dapat digunakansebagai filler pada pembuatan komposit [14]. Dikatakan bahwa penambahan serat pisang dapat menambah kuat tekan campuran beton serat pisang [15]. Salah satu serat alam yang banyak digunakan adalah serat pelepah pisang, penggunaan serat pelepah pisang sebagai bahan komposit merupakan langkah yang baik guna mengurangi timbunan pelepah pisang yang berserakan dikebun dan juga untuk menaikkan nilai ekonimis dari pelepah pisang tersebut [16]. Serat pelepah pisang 
mempunyai sifat mekanik yang lebih kaku, tangguh dan lebih kokoh. Selain itu, serat pisang memiliki rongga antar serat [17].

Tujuan dari diadakannya penelitian ini adalah memanfaatkan hasil limbah marmer dan serat batang pisang yang seringkali tidak dimanfaatkan dengan baik serta diharapkan mampu menjadi inovasi baru untuk bahan campuran pembuatan beton agar meningkatkan nilai kuat tekan dan mengurangi berat jenis pada beton.

\section{Studi Literatur}

Penelitian yang dilakukan oleh Istiqomah, Shanti Kurnia dengan penelitian yang berjudul "PENGARUH LIMBAH MARMER SEBAGAI BAHAN PENGISI PADA BETON" (2013) pada penelitian ini penulis memiliki tujuan untuk mengetahui pengaruh kuat tekan dengan penambahan limbah marmer sebagai filler dalam campuran beton, Sehingga menghasilkan kesimpulan pengujian kuat tekan pada beton mengalami peningkatan pada prosentase 10-20\%. [10]

\subsection{Material Penyusun Beton}

\subsubsection{Semen Portland}

Semen merupakan salah satu bahan dasar utama konstruksi bangunan, sehingga menjadikan semen sebagai komoditi yang strategis [18]. Semen portland merupakan semen yang dihasilkan dengan cara menghaluskan klinker yang terdiri dari silikat kalsium yang bersifat hidrolis dengan bahan tambahan berupa gypsum [19].Semen portland berfungsi sebagai perekat antara butiran-butiran agregat dan juga mengisi rongga-rongga antara butiran-butiran agregat agar terjadi suatu massa yang padat. Semen portland memerlukan air untuk berlangsungnya reaksi kimia pada proses hidrasi sehingga semen mengeras bersama dengan butiran-butiran agregat sehingga membentuk massa yang padat. Bahan dasar pembetuk semen Portland terdiri dari kapur, silika, alumina dan oksida besi. Oksida tersebut bereaksi membentuk suatu produk yang terbentuk akibat peleburan [20].

\subsubsection{Agregat Halus}

Agregat halus merupakan pengisi yang berupa pasir yang mempunyai BJ $1400 \mathrm{~kg} / \mathrm{m}$. Agregat halus yang baik harus bebas bahan organik, lempung, partikel yang lebih kecil, atau bahan-bahan lain yang dapat merusak campuran. Variasi ukuran dalam suatu campuran harus mempunyai gradasi yang baik. Berdasarkan Anonim 1, agregat halus diartikan sebagai pasir alam yang dihasilkan dari bagian dari desintegrasi alami atau batu yang dihasilkan oleh industri 
pemecah batu yang mempunyai ukuran butiran sebesar 4,75 mm [21]. Dalam literatur disebutkan bahwa beton yang dibuat dengan menggunakan agregat dari hasil pemecah-an batu memberikan kinerja yang lebih baik dibandingkan dengan yang dibuat dengan menggunakan agregat alami un- tuk kondisi lainnya konstan [22].

\subsubsection{Agregat Kasar}

Agregat Kasar didefinisikan sebagai hasil disintregasi alami dari batuan atau berupa batu pecah yang didapat dari industri pemecah batu, karakteristik agregat kasar dapat mempengaruhi kekuatan beton dan daya tahan beton terhadap segala cuaca dan efek yang merusak lainnya. Agregat kasar mempunyai ukuran berkisar antara 4,75 mm sampai $40 \mathrm{~mm}$.. Agregat yang akan digunakan merupakan agregat yang berasal dari Kecamatan mantup [23] Batu split (batu koral) adalah salah satu jenis batu material bangunan yang di peroleh dengan cara membelah atau memecah batu yang berukuran besar menjadi kecil. Batu split juga sering disebut dengan nama batu belah [24].

\subsubsection{Air}

Air yang digunakan dalam pembuatan dan perawatan beton adalah air bersih tidak berwarna, tidak berbau dan tidak berasa agar dapat menghasilkan beton yang berkualitas. Pengaruh proses hidrasi antara air dengan semen sangat mempengaruhi workability pada beton. Proses hidrasi secara penuh dicapai dengan terjadinya rasio semen diatas 1.00. Proses ini diambil dari lapisan yang telah terhidrasi dari permukaan air semen. Seluruh proses akan berlangsung dalam beberapa bulan hingga dapat mencapai hasil yang maksimum. Selain itu air juga digunakan untuk metode curing dalam menjamin proses pengerasan beton yang sempurna [25].

\subsection{Pengujian Kuat Tekan Beton}

$$
K=\frac{P}{A}
$$

Dimana :

$\mathrm{K}=$ Kuat Tekan Beton $(\mathrm{kg} / \mathrm{cm} 2)$

$\mathrm{P}=$ Gaya tekan aksial, dinyatakan dalam newton $(\mathrm{N})$

$\mathrm{A}=$ Luas penampang melintang benda uji, $\left(\mathrm{mm}^{2}\right)$

Sumber : SNI 1974-2011 [26]

Kuat tekan merupakan salah satu metode uji untuk menentukan mutu dan kualitas beton yang ditentukan dengan hasil uji laboratorium dengan membuat sampel benda uji. 
Indikasi pembuatan beton dikatakan berhasil dengan pencapaian kuat tekan b eton yang telah sesuai dengan yang sudah direncanakan dalam mix design. Dalam pekermbangan saat ini banyak sekali ditemukan beton model baru hasil modifikasi, seperti beton berkekuatan sangat tinggi, beton fiber, beton ringan, beton semprot, beton berkekuatan tinggi, beton mampat sendiri dll. Dan pada saat ini beton merupakan suatu bahan bangunan yang paling banyak digunakan di dunia. Menurut SNI 1974-2011 tes standar untuk kekuatan tekan beton dengan silinder sampel dengan diameter $15 \mathrm{~cm}$ dan tinggi $30 \mathrm{~cm}$ dihitung dengan membagi beban maksimum yang dicapai dengan luas permukaan sampel beton [27].

\section{Metodologi Penelitian}

Metode penelitian adalah langkah-langkah yang digunakan untuk sebuah penelitian. Sehingga dalam suatu penelitian diharapkan mampu menyajikan sebuah hasil. Dimana hasil tersebut dapat dipertanggungjawabkan secara ilmiah. Pada penelitian ini penulis menggunakan metode literature dan metode eksperimental. Dimana hasil dari penelitian tersebut mampu menunjukkan hasil sebab dan akibat antara variabel satu dengan yang lainnya.

\subsection{Rencana Penelitian}

Penelitian yang menggunakan metode eksperimental yaitu dilaksanakan secara langsung. Penelitian dilakukan di Laboratorium Teknik Sipil Universitas Kadiri dengan mengacu pada SNI. Pada penelitian ini menggunakan benda uji silinder dengan ukuran 15 x 30 cm yang berjumlah 12 sampel dengan variasi campuran limbah marmer dan serat batang pisang yakni 10\%, 20\%, 30\% yang akan diuji pada umur 28 hari.

\subsection{Alur Penelitian}

Tahapan penelitian ini dimulai dari pengumpulan material dari bahan penyusun beton, kemudian dilakukan pemeriksaan pada material dengan melakukan pengujian bahan pada agregat, setelah itu memperhitungkan rencana campuran/ mix design dan langkah selanjutnya adalah dengan pembuatan campuran sesuai dengan jobmix design yang dilakukan dengan mencetak pada silinder benda uji, kemudian sampel benda uji dilakukan perawatan (curing) selama 28 hari. Setelah mencapai umur 28 hari maka beton dapat dilakukan pengujian kuat tekan beton, dengan tahap penelitian yang disajikan pada gambar berikut : 


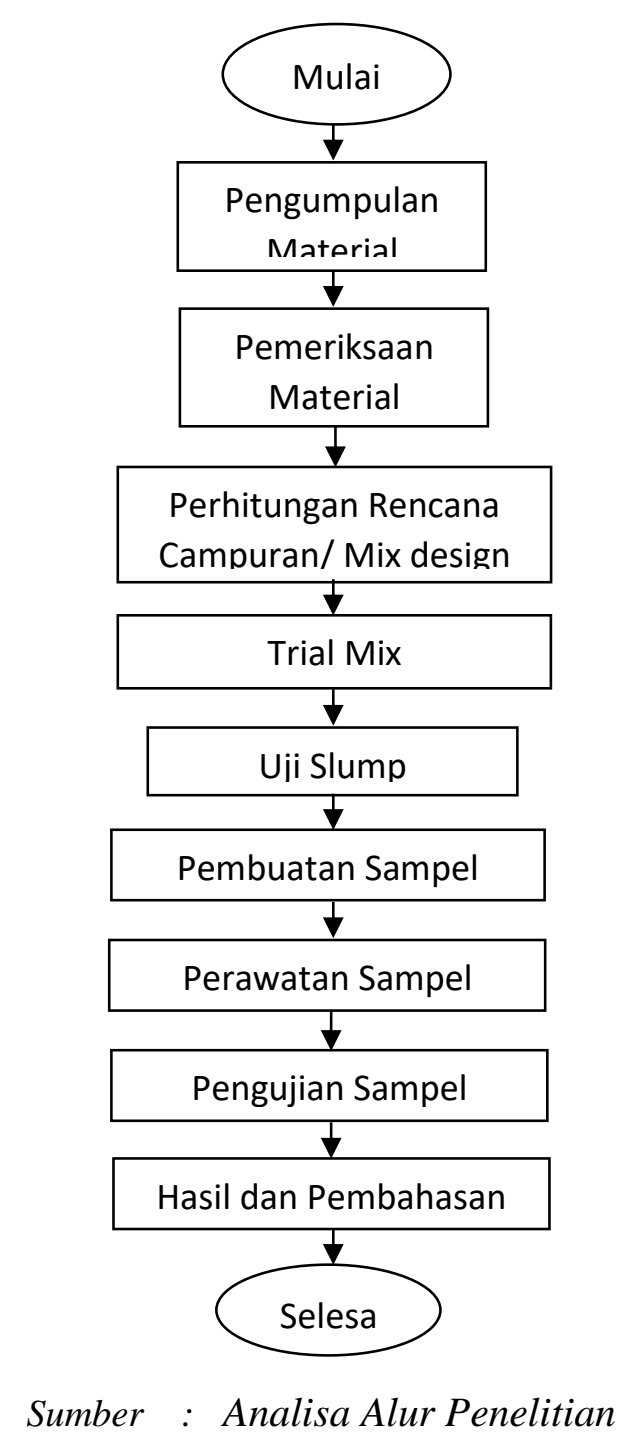

Gambar 1. Alur Penelitian

\section{Hasil dan Diskusi}

\subsection{Hasil Pengujian Nilai Slump}

Dari hasil pencampuran beton atau mix design telah didapatkan nilai slump pada masing-masing variasi campuran benda uji yang telah disajikan pada tabel dan grafik sebagai berikut :

Tabel 1. Nilai Slump

\begin{tabular}{ccc}
\hline $\begin{array}{c}\text { Variasi } \\
\text { Campuran }\end{array}$ & $\begin{array}{c}\text { Kode } \\
\text { Benda Uji }\end{array}$ & $\begin{array}{c}\text { Slump } \\
(\mathrm{cm})\end{array}$ \\
\hline $0 \%$ & BT-N & 2 \\
$10 \%$ & BT-A & 0.9 \\
$20 \%$ & BT-B & 2.7 \\
$30 \%$ & BT-C & 1.2 \\
\hline
\end{tabular}

Sumber : : Analisa Hasil Uji Nilai Slump 
Hasil pengujian slump menunjukkan bahwa nilai slump tertinggi terdapat pada prosentase $20 \%$ yaitu $2.7 \mathrm{~cm}$.

\subsection{Hasil Pengujian Kuat Tekan}

Pengujian kuat tekan dilakukan pada setiap beton normal dan beton variasi campuran $10 \%, 20 \%, 30 \%$ pada umur beton 28 hari dengan diperoleh hasil sebagai berikut :

Tabel 2. Kuat Tekan Beton Normal dan Beton Variasi

\begin{tabular}{cccc}
\hline Prosentase & $\begin{array}{c}\text { Kode } \\
\text { Benda Uji }\end{array}$ & $\begin{array}{c}\text { Kuat Tekan } \\
(\mathrm{Mpa})\end{array}$ & $\begin{array}{r}\text { Kuat Rata-rata } \\
(\mathrm{Mpa})\end{array}$ \\
\hline $0 \%$ & BT-N & 22,27 & 26,94 \\
& & 26,50 & \\
$10 \%$ & BT-K & 32,05 & 18,86 \\
& & 19,92 & \\
$20 \%$ & BT-K & 18,33 & 18,23 \\
& & 18,33 & \\
$30 \%$ & & 18,98 & 17,54 \\
\hline
\end{tabular}

Sumber : Analisa Hasil Uji Kuat Tekan Beton Normal dan Beton Variasi

Dari hasil tabel kuat tekan diatas didapatkan kuat tekan rata rata tertinggi pada prosentase $10 \%$ dengan nilai kuat tekan 18,86 Mpa. Hasil uji kuat tekan pada table 2 dapat disajikan grafik kuat tekan sebagai berikut akan disajikan dengan grafik nilai kuat tekan ratarata pada gambar berikut :

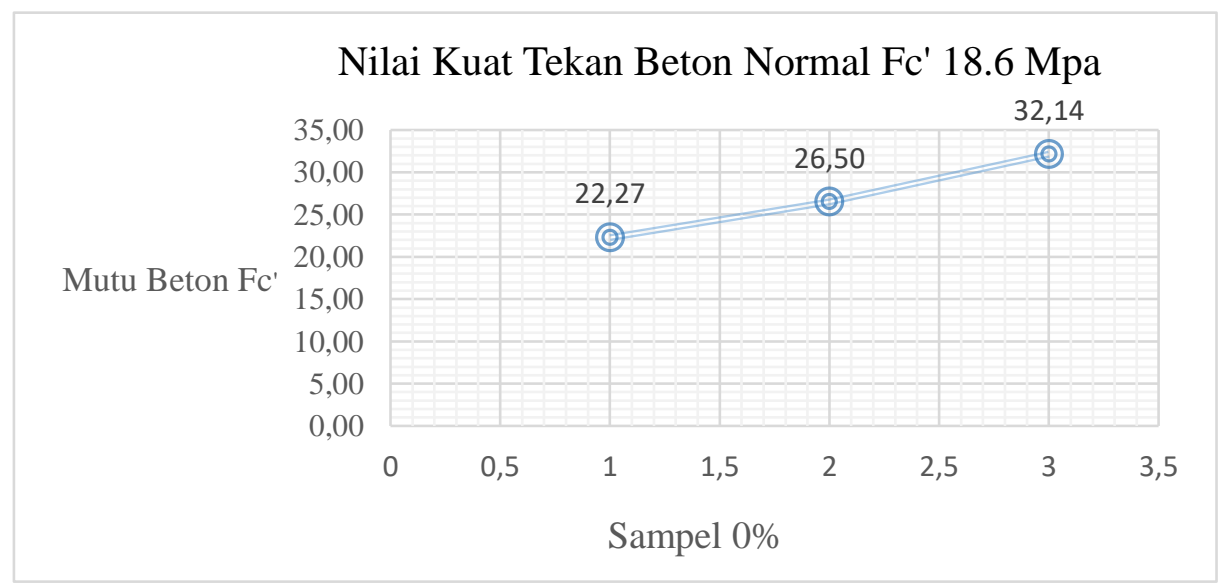

Sumber : Analisa Hasil Uji Nilai Kuat Tekan Beton Normal

Gambar 2. Grafik Nilai Kuat Tekan Beton Normal

Pada ketiga sampel beton normal didapat nilai kuat tekan berturut turut yaitu 22,7 Mpa, 26,50 Mpa, dan 32,14 Mpa. Hasil tersebut menujukkan bahwa pada sampel normal telah 
melebihi mutu awal yang direncanakan.

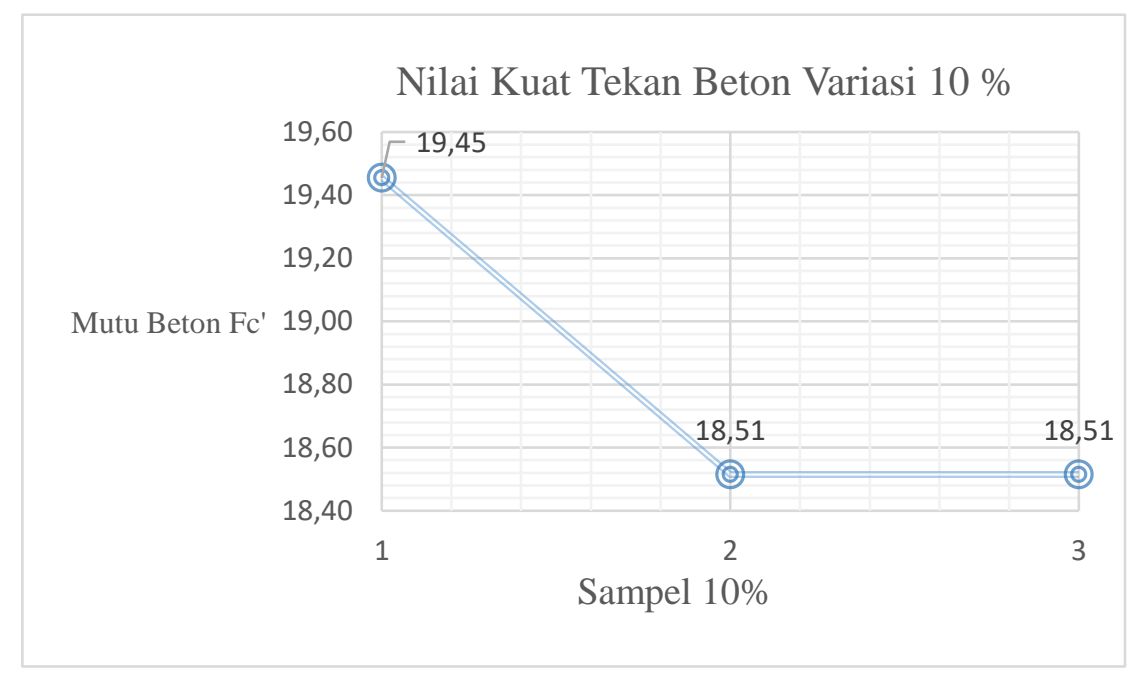

Sumber : Analisa Hasil Uji Nilai Kuat Tekan Beton Variasi $10 \%$.

Gambar 3. Grafik Nilai Kuat Tekan Beton Variasi 10\%.

Pada Gambar 3. menunjukkan bahwa sampel beton variasi $10 \%$ didapat nilai kuat tekan berturut turut yaitu 18,51 Mpa, 18,51 Mpa, dan 19,45 Mpa . Hasil tersebut menujukkan bahwa pada sampel variasi $10 \%$ belum memenuhi mutu awal yang direncanakan.

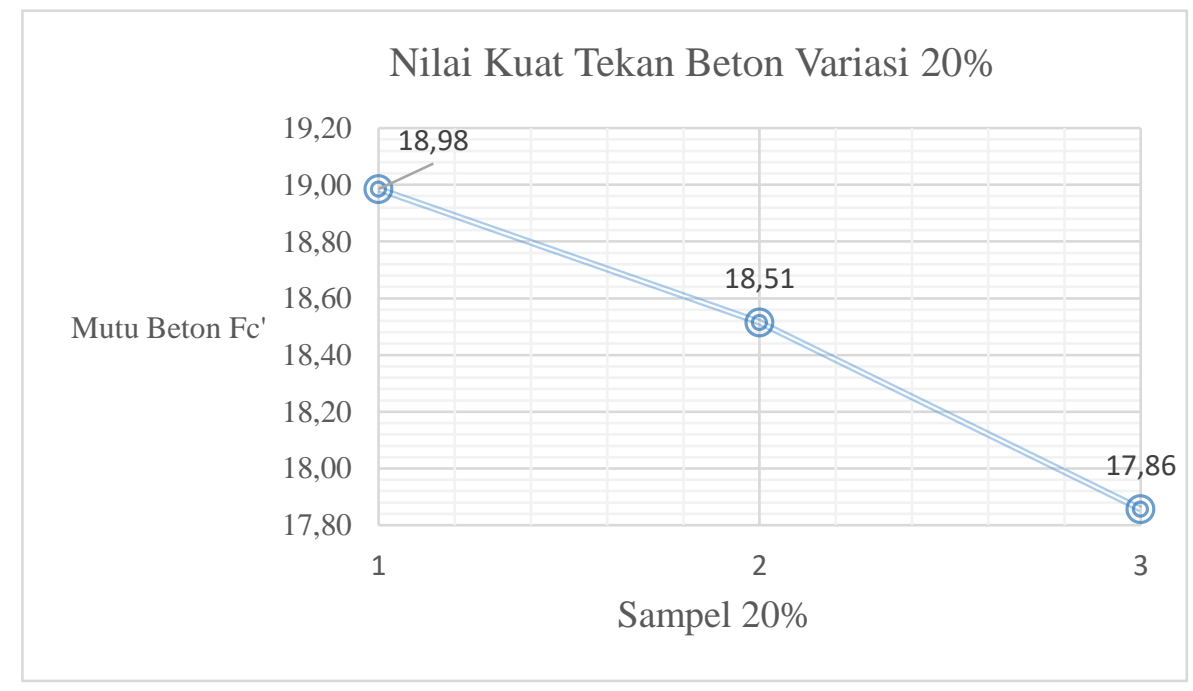

Sumber : Analisa Hasil Uji Nilai Kuat Tekan Beton Variasi $20 \%$.

Gambar 4. Grafik Nilai Kuat Tekan Beton Variasi $20 \%$.

Pada ketiga sampel beton variasi $20 \%$ didapat nilai kuat tekan berturut turut yaitu 17,86 Mpa, 18,51 Mpa, dan 18,98 Mpa. Hasil tersebut menujukkan bahwa pada sampel variasi $20 \%$ belum memenuhi mutu awal yang direncanakan. 


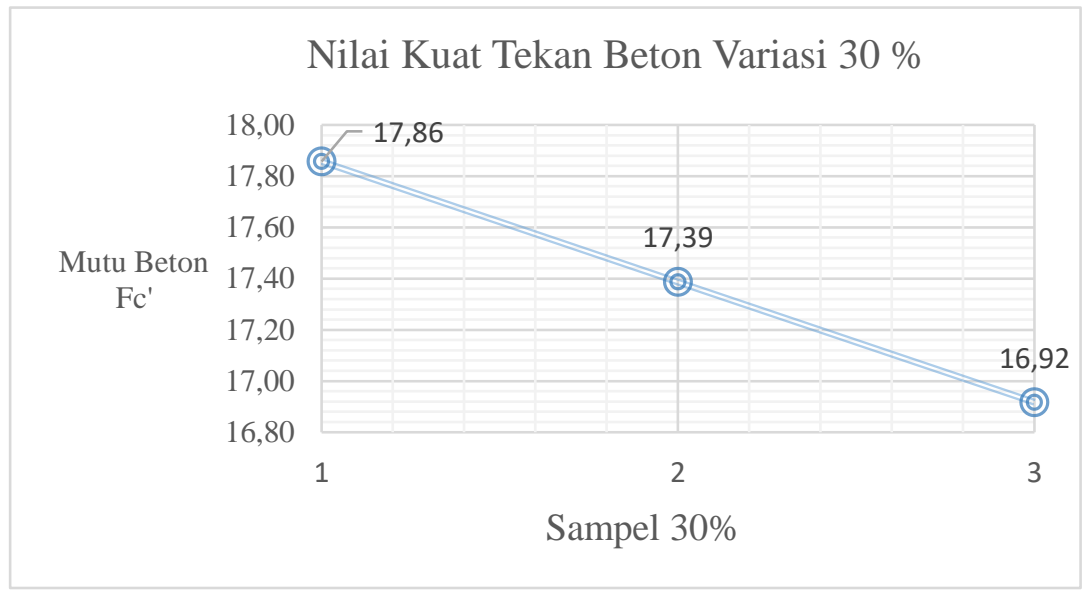

Sumber : Analisa Hasil Uji Kuat Tekan Beton Variasi $30 \%$.

Gambar 5. Grafik Nilai Kuat Tekan Beton Variasi $30 \%$.

Pada ketiga sampel beton variasi $30 \%$ didapat nilai kuat tekan berturut turut yaitu 16,92 Mpa, 17,39 Mpa, dan 17,86 Mpa. Hasil tersebut menujukkan bahwa pada sampel variasi $30 \%$ belum memenuhi mutu awal yang direncanakan.

\section{Kesimpulan dan Saran}

\subsection{Kesimpulan}

Berdasarkan hasil dari penelitian tentang pengujian kuat tekan dengan penambahan limbah marmer dan serat batang pisang dalam pembuatan beton yang telah dilaksanakan di Laboratorium Teknik Sipil Universitas Kadiri yang telah dilakukan dan hasil analisa data yang telah didapatkan dari pengamatan tersebut, maka dapat ditarik kesimpulan sebagai berikut bahwa :

1. Nilai kuat tekan beton normal adalah $18,85 \mathrm{Mpa}$, Nilai kuat tekan beton dengan variasi prosentase $10 \%, 20 \%$ dan $30 \%$ berturut-turut adalah 17, $94 \mathrm{Mpa}, 17,52 \mathrm{Mpa}$ dan 16,62 Mpa.

2. Nilai slump pada beton normal adalah $2 \mathrm{~cm}$, nilai slump pada beton variasi $10 \%$ adalah 0,9 $\mathrm{cm}$, nilai slump pada beton variasi $20 \%$ adalah $2,7 \mathrm{~cm}$, dan nilai slump pada beton variasi $30 \%$ adalah $1,2 \mathrm{~cm}$.

\subsection{Saran}

Berdasarkan hasil dari penelitian tentang pengujian kuat tekan dengan penambahan limbah marmer dan serat batang pisang dengan variasi prosentase $10 \%, 20 \%$ dan $30 \%$ penulis memberikan saran yang sekiranya dapat dipertimbangkan yaitu serat pisang dapat digunakan 
campuran beton dengan memperhatikan ukuran dan pemotongan serat. Semakin tipis ukuran pemotongan serat akan memberikan hasil yang lebih maksimal serta limbah marmer dan serat batang pisang perlu dicoba dengan variasi persentase 8-12\% agar menghasilkan hasil yang lebih maksimal 


\section{Daftar Pustaka}

[1] D. H. Prayogo, A. Ridwan, and S. Winarto, "PEMANFAATAN LIMBAH GYPSUM BOARD DAN BATU BATA MERAH UNTUK SUBSTITUSI SEMEN PADA PEMBUATAN BETON," Jurmateks, vol. 2, no. 2, pp. 333-342, 2019.

[2] E. W. Setyowati, "Kuat Tekan Beton Limbah Batu Onix Tulungagung," J. Media Tek. Sipil, vol. 14, no. 2, p. 140, 2016, doi: 10.22219/jmts.v14i2.3703.

[3] J. He and X. Shi, "Accelerated Laboratory Assessment of Discrete Sacrificial Anodes for Rehabilitation of Salt-Contaminated Reinforced Concrete," J. Mater. Civ. Eng., vol. 32, no. 11, p. 04020344, 2020, doi: 10.1061/(asce)mt.1943-5533.0003374.

[4] A. Y. Bintoro, A. D. Limantara, and S. Winarto, "EVALUASI KEKUATAN CONCBLOCK DENGAN AGREGAT HALUS DAN AGREGAT KASAR DARI TEMPURUNG KELAPA,”Jurmateks, vol. 1, no. 1, pp. 160-171, 2018.

[5] S. Ghosn, N. Cherkawi, and B. Hamad, "Studies on Hemp and Recycled Aggregate Concrete," Int. J. Concr. Struct. Mater., vol. 14, no. 1, 2020, doi: 10.1186/s40069-02000429-6.

[6] E. Siswanto, "Penambahan Fly Ash Dan Serat Serabut Kelapa Sebagai Bahan Pembuatan Beton," UKaRsT, vol. 3, no. 1, p. 48, 2019, doi: 10.30737/ukarst.v3i1.352.

[7] B. Tiwari, B. Ajmera, R. Maw, R. Cole, D. Villegas, and P. Palmerson, "Mechanical properties of lightweight cellular concrete for geotechnical applications," J. Mater. Civ. Eng., vol. 29, no. 7, pp. 1-7, 2017, doi: 10.1061/(ASCE)MT.1943-5533.0001885.

[8] A. F. Kariri and N. A. Affandy, "Analisis Kuat Tekan Beton Dengan Bahan Tambah Pelepah Pisang Pada Beton Mutu K-200,” Ukarst Univ. Kadiri Ris. Tek. Sipil, vol. 2, no. 2, pp. 26-34, 2018.

[9] M. Ibrahim, A. Ahmad, M. S. Barry, L. M. Alhems, and A. C. Mohamed Suhoothi, "Durability of Structural Lightweight Concrete Containing Expanded Perlite Aggregate," Int. J. Concr. Struct. Mater., vol. 14, no. 1, 2020, doi: 10.1186/s40069-020-00425-w.

[10] I. dan S. Kurnia, "Pengaruh Limbah Marmer Sebagai Bahan Pengisi Pada Beton (175S)," Tek. Sipil, Univ. Sebel. Maret Surakarta, vol. 7, no. KoNTekS 7, pp. 185-190, 2013.

[11] X. Zou and L. H. Sneed, "Bond Behavior Between Steel Fiber Reinforced Polymer (SRP) and Concrete," Int. J. Concr. Struct. Mater., vol. 14, no. 1, pp. 1-17, 2020, doi: 10.1186/s40069-020-00420-1.

[12] A. I. Candra, H. Wahyudiono, S. Anam, and D. Aprillia, "KUAT TEKAN BETON Fc ' $21,7 \mathrm{MPa}$ MENGGUNAKAN WATER REDUCING AND HIGH RANGE ADMIXTURES," J. CIVILA, vol. 5, no. 1, pp. 330-340, 2020.

[13] A. I. Candra, A. Ridwan, S. Winarto, and Romadhon, "Correlation of Concrete Strength and Concrete Age K-300 Using Sikacim ${ }^{\circledR}$ Concrete Additive and Master Ease 5010," J. Phys. Conf. Ser., vol. 1569, no. 4, 2020, doi: 10.1088/1742-6596/1569/4/042032.

[14] S. Supraptiningsih, "Pengaruh serbuk serat batang pisang sebagai filler terhadap sifat mekanis dari komposit PVC-CaCO3," Maj. Kulit, Karet, dan Plast., vol. 28, no. 2, p. 79, 2012, doi: 10.20543/mkkp.v28i2.108. 
[15] S. Hani and . R., "Pengaruh Campuran Serat Pisang Terhadap Beton," Educ. Build., vol. 4, no. 1, pp. 40-45, 2018, doi: 10.24114/eb.v4i1.10043.

[16] A. Salam and S. D. Hartantyo, "Pengaruh Penambahan Serat Pelepah Pisang Pada Pembuatan Paving Block K-175," J. CIVILA, vol. 2, no. 2, p. 8, 2017, doi: 10.30736/cvl.v2i2.73.

[17] R. Randa and A. Mahyudin, "Pengaruh Persentase Serat Pelepah Pisang Terhadap Sifat Fisik dan Mekanik Papan Semen-Foam agent," J. Fis. Unand, vol. 8, no. 1, pp. 46-51, 2019, doi: 10.25077/jfu.8.1.46-51.2019.

[18] I. Purnawan and A. Prabowo, "Pengaruh Penambahan Limestone terhadap Kuat Tekan Semen Portland Komposit," J. Rekayasa Proses, vol. 11, no. 2, p. 86, 2018, doi: 10.22146/jrekpros.31136.

[19] S. W. I. Pratama, N. Rauf, E. Juarlin, S. W. I. Pratama, N. Rauf, and E. Juarlin, "Pembuatan dan Pengujian Kualitas Semen Portland Yang Diperkaya Silikat Abu Ampas Tebu ( Fabrication and Quality Test of Cement Portland With Enriched by Silicate Sugarcane Bagasse Ash )," J. Fis. FMIPA Unhas, pp. 1-5, 2014.

[20] Susilowati, "PEMANFAATAN SERBUK MARMER SEBAGAI BAHAN ALTERNATIF PENGGANTI SEMEN PADA CAMPURAN BETON NORMAL Susilowati*," no. 4, pp. 16-24.

[21] K. Amna, Wesli, and Hamzani, "Pengaruh Penambahan Serat Tandan Sawit Terhadap Kuat Tekan Dan Kuat Lentur Beton,” J. Din., vol. 4, no. 2, pp. 11-20, 2014.

[22] I. M. Salain, "Pengaruh jenis semen dan jenis agregat kasar terhadap kuat tekan beton," Teknol. dan Kejuru., vol. 32, no. 1, pp. 63-71, 2009.

[23] A. I. Candra, E. Gardjito, Y. Cahyo, and G. A. Prasetyo, "Pemanfaatan Limbah Puntung Rokok Filter Sebagai Bahan Campuran Beton Ringan Berpori," UKaRsT, vol. 3, no. 1, p. 82, 2019, doi: 10.30737/ukarst.v3i1.365.

[24] E. Gardjito, A. I. Candra, and Y. Cahyo, "Pengaruh Penambahan Batu Karang Sebagai Substitusi Agregat Halus Dalampembuatan Paving Block," UKaRsT, vol. 2, no. 1, p. 35, 2018, doi: 10.30737/ukarst.v2i1.374.

[25] Elhusna and A. Gunawan, "PERBAIKAN PERILAKU KUAT TEKAN BETON AIR RAWA DENGAN METODE PENYARINGAN AIR,” J. Inersia, vol. 6, no. 1, pp. 7380, 2014.

[26] S. Winarto, "Pemanfaatan Serat Ijuk Sebagai Material Kemampuan Beton Menahan Beban Tekan Studi Kasus : Pembangunan Homestay Singonegaran Kediri," UKaRsT, vol. 1, no. 1, pp. 1-38, 2017.

[27] H. Pratikto, "Penelitian Kuat Uji Tekan Beton Dengan Memanfaatkan Limbah Beton Yang Tidak Terpakai," UKaRsT, vol. 1, no. 2, p. 21, 2017, doi: 10.30737/ukarst.v1i2.411. 